\title{
Current and future aluminium strategies for sustainable automobile transport systems
}

\author{
Philippe Lequeu \\ CONSTELLIUM Packaging and Automotive Rolled Products, Voreppe, France
}

\begin{abstract}
The aluminium industry is facing the fascinating challenge of automotive light-weighting, driven by the worldwide evolution of environmental regulations. Challenges include extending production capacities of auto body sheets as well as geographical footprint, and developing an appropriate portfolio of light-weighting affordable new alloys and solutions, all this with sustainability in mind. This paper describes how Constellium, as one of the European leaders in advanced aluminium based solutions for the transport market, is addressing all these challenges in its strategic, operational and sustainability agendas.
\end{abstract}

\section{INTRODUCTION}

The world-wide automotive industry is facing the huge challenge of sustainability. Regulations on $\mathrm{CO}_{2}$ emissions are all converging the same way, with significant reductions to be achieved along the next decade (see Fig. 1), and Europe is leading the way with targets of $95 \mathrm{~g} \mathrm{CO} / \mathrm{km}$ by 2020 , from a 2010 baseline figure of around $140 \mathrm{~g} \mathrm{CO}_{2} / \mathrm{km}$. Axes to achieve such targets are known and combine light-weighting, aerodynamics, rolling resistance and engine technologies. Thanks to its intrinsic density advantage versus steel and typical recognized weight savings in the range $30-50 \%$, aluminium certainly offers the best cost/weight balance among competing solutions. But the aluminium industry is facing important challenges in a technically, financially and environmentally constrained environment, like need for:

(i) The development of production capacities to deliver on double-digit growth opportunities

(ii) An appropriate portfolio of light-weighting alloys and solutions

(iii) An acceptable extra cost of weight saving

(iv) A world-wide geographical footprint

(v) Minimum compatibility of solutions with current steel-based processing routes

(vi) Sustainable solutions.

\section{STRATEGIES FOR AUTOMOTIVE ALUMINIUM BODY SHEET}

Recent market studies published by Ducker [2] call for a more than $200 \%$ increase of various typical body and closures parts, from $11.5 \mathrm{~kg}$ to $27 \mathrm{~kg}$ per vehicle in the period 2012 to 2020 . Such a growth puts pressure on the aluminium industry to both increase production capacities and act as global suppliers, subjects for which Constellium is currently investigating options.

Increasing production capacities means to at least invest in additional continuous heat-treatment and chemical conversion capacities, leading to investments in the range of $50-60 \mathrm{M} €$ for every such equipment, for a production extra capacity of around 70-80 kt per year. Hot and cold rolling capacities are somewhat easier to access, avoiding in many cases hundreds of millions of investments through green fields or other means.

It is clear that move towards converting incumbent steel solutions to other materials, would they be higher strength steels, aluminium, magnesium, or composites, will highly depend on what the car manufacturers are ready to pay for any kilogram saved. In this regards, typical figures in the range of 2 to $8 € / \mathrm{kg}$ saved are commonly recognized as maximum values, to which aluminium in most cases can fit.

It is thought that the most efficient ways to reduce metal price for a given part is to increase the material utilization as well as to down-gauge. Improvement in material utilization, that is the amount of metal used versus purchased, can be achieved thanks to close partnerships with the OEMs, better understanding the material waste profile along the manufacturing route, as well as selling just the quantity of metal needed, and where it is needed. This can be achieved for example by appropriate tailoring techniques, which have already been proposed (like tailor-welded blanks) and continue to be developed by Constellium in its corporate Research and Technology Centre of Voreppe, France.

As far as down-gauging and light-weighting are concerned, aluminium is not alone competing with conventional steels, and the aluminium industry needs to raise the bar to best compete against the high strength steels, magnesium, and composites. Table below gives some highlights of the weight saving and cost penalties of these various material options:

\begin{tabular}{|c|c|c|}
\hline Material & $\begin{array}{c}\text { Price typ./ } \\
\text { kg }\end{array}$ & $\begin{array}{c}\text { Weight saving } \\
\text { vs steel }\end{array}$ \\
\hline Steels- UHSS/AHSS & $0.8-1.5 €$ & $10-20 \%$ \\
\hline Aluminium & $3-5 €$ & $30-50 \%$ \\
\hline Magnesium & $10-20 €$ & $40-60 \%$ \\
\hline Carbon Fiber Composites & $40-80 €$ & $60-70 \%$ \\
\hline
\end{tabular}

In this search for light-weighting, Constellium has developed over the last years a family of dedicated 


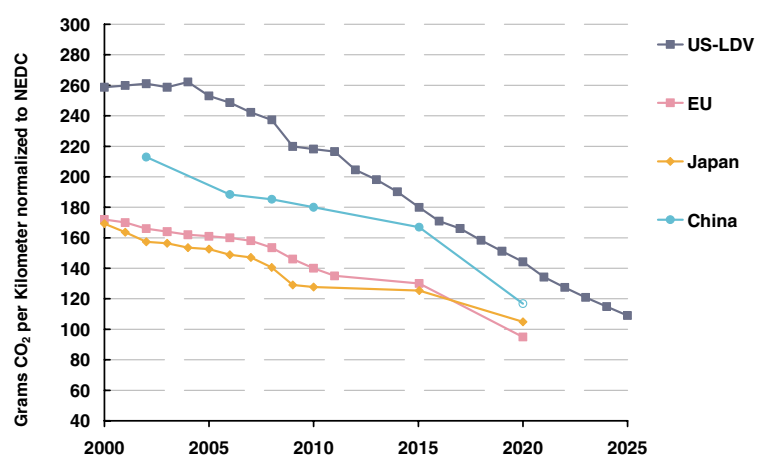

Figure 1. Evolution of WW regulation on $\mathrm{CO}_{2}$ emissions over the next decades - Inspired from [1].
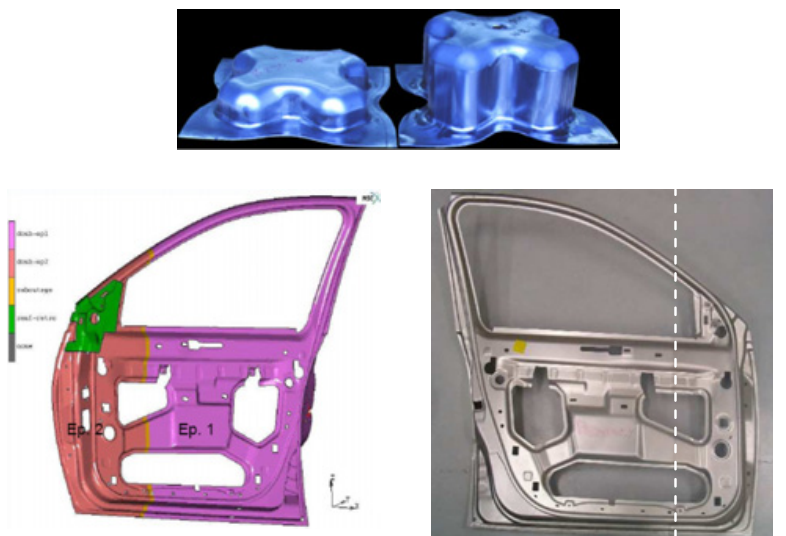

Figure 2. Top: illustration of the warm $\left(250^{\circ} \mathrm{C}\right.$ - right $)$ versus cold (room $\mathrm{T}^{\circ}-$ left) forming capability of a typical $7 \mathrm{xxx}$ alloy Bottom: tailor-welded door inner structure.

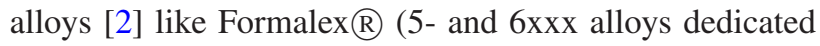
to improved formability), Strongalex $\mathbb{R}$ (6xxx alloys

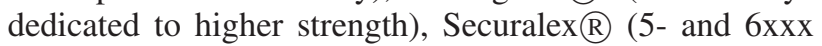
alloys dedicated to crash \& safety improved performance),

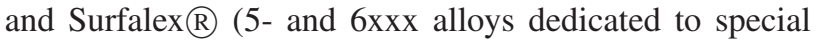
roping-free \& hemming improved surfaces). All these alloys are currently produced in the Neuf-Brisach plant. An ultra-high strength version at $400 \mathrm{MPa}$ yield stress is

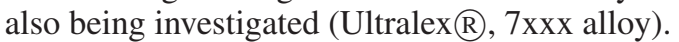

Studies on adjacent customer technologies are also on Constellium's agenda in order to adapt accordingly the alloy offer and propose innovative concepts. Preliminary studies were launched and are now at various Technology readiness levels in various fields like forming (warmforming), joining (laser, cold-metal-transfer, friction stir) and surface treatment (surface texturing, chemical conversion), without mentioning more "exotic" confidential step change concepts. Some illustrations are provided in Figure 2 below.

Finally, the aluminium industry needs to address the environmental challenge and answer the demand for sustainable solutions. Constellium is promoting an endof-life approach, rather than a pure recycled content one, based on its higher environmental benefit associated to the predominant impact of the use phase in the complete life-cycle assessment (LCA). In this regard, LCA is the right tool to be used, since integrating production, use phase and recycling savings. Development of new alloys, as summarized above, is an obvious mean for reducing $\mathrm{CO}_{2}$ emissions through light-weighting, with around $10 \mathrm{~g}$ of $\mathrm{CO}_{2} / \mathrm{km}$ saved for every $100 \mathrm{~kg}$ light-weighting. But Constellium is also active in recycling and in energy reduction programs along the internal processing route, like for example recent investments in energy-reducing oxy-fuel burners and electromagnetic casting technologies. Constellium has also recently joined as a co-initiator the Aluminium Stewardship Initiative, with a target to define the first standards for a transparent and sustainable aluminium.

\section{CONCLUSIONS}

Driven by the world-wide evolution of regulation towards lower $\mathrm{CO}_{2}$ emissions, the aluminium industry is facing a fascinating but challenging opportunity with an expected exponential growth in the years to come. Main challenge is about meeting the customer needs, among which investing in the appropriate production capacities, and developing a portfolio of alloys and solutions for light-weighting purposes, with in mind the cost and sustainability aspects. As one of the key players in Europe for producing such automotive sheet, Constellium Packaging and Automotive Rolled Product division is addressing all these challenges.

\section{References}

[1] The International Council of Clean Transportation (ICCT) - Global standards - www.theicct.org

[2] "EAA Aluminium penetration in car - Final report", Ducker Worldwide, March 12, 2012

[3] H. Ribes and A. Afseth, "Meeting the most demanding body-in-white requirements with Aluminium sheet", Automotive Circle Conference, Bad Nauheim, May 2011 